\title{
Adjacent Disc Stress Following Floating Lumbar Spine Fusion: A Finite Element Study
}

\author{
Gunti Ranga Srinivas ${ }^{1}$, Malhar N. Kumar ${ }^{2}$, Anindya Deb ${ }^{3}$ \\ ${ }^{1}$ Mahindra Technical Academy, Chennai, India \\ ${ }^{2}$ HOSMAT Hospital, McGrath Road, Bangalore, India \\ ${ }^{3}$ Centre for Product Design and Manufacturing, Indian Institute of Science, Bangalore, India
}

\begin{abstract}
Study Design: Experimental study.
Purpose: The study aimed to develop a finite element (FE) model to determine the stress on the discs adjacent to the fused segment following different types of floating lumbar spinal fusions.

Overview of Literature: The quantification of the adjacent disc stress following different types of floating lumbar fusions has not been reported. The magnitude of the stress on the discs above and below the floating fusion remains unknown.

Methods: A computer-aided engineering-based approach using implicit $\mathrm{FE}$ analysis was employed to assess the stress on the lumbar discs above and below the floating fusion segment (L4-L5) following anterior and posterior lumbar spine fusions at one, two, and three levels (with and without instrumentation).

Results: Both discs suprajacent and infrajacent to the floating fusion experienced increased stress, but the suprajacent disc experienced relatively high stress level. Instrumentation increased the stress on the discs suprajacent and infrajacent to the floating fusion, but the magnitude of stress on the suprajacent disc remained relatively high.

Conclusions: The FE model was employed under similar loading and boundary conditions to provide quantitative data, which will be useful for clinicians to understand the probable long-term effects of floating fusions.
\end{abstract}

Keywords: Lumbar vertebrae; Spinal fusion; Intervertebral disc; Intervertebral disc degeneration

\section{Introduction}

The phenomenon of adjacent disc degeneration (ASD) following lumbar spine fusion has received considerable attention from spine surgeons. However, only a few studies have focused on the effects of "floating fusion" on the adjacent discs. For the purpose of clarity, we defined "floating fusion" as a fusion of native, unfused discs above and below the fusion segment. Classically, monosegmental floating fusion is performed for degenerative spondylolis- thesis of L4 over L5 vertebra following degenerative disc disease of the L4-L5 disc. "Floating fusion" should be distinguished from the concept of "floating disc," which was defined by Derincek et al. [1] as a "normal disc left alone between two surgically fused areas". Thus, a floating L4L5 disc refers to an unfused L4-L5 disc that lies between L3-L4 and L5-S1 fusion segments. The present study focuses on "floating fusion" and not on "floating discs." We adopted the terminology recommended by Rousseau and Lazennec [2] who labeled the disc cranial to the floating

Received Oct 26, 2016; Revised Dec 10, 2016; Accepted Jan 3, 2017

Corresponding author: Malhar N. Kumar

HOSMAT Hospital, McGrath Road, Bangalore, India, 560025

Tel: +91-093426-33667, Fax: +91-80255-93796, E-mail: docmnkumar@gmail.com 
fusion segment as the "suprajacent disc" and the disc caudal to the floating fusion as the "infrajacent disc".

Brodsky et al. [3] published their experiences (spanning over three decades) with the floating fusion of the L4L5 segment in a large cohort of 184 patients and reported poor outcomes in only $2 \%$ of them. Only $2.7 \%$ of the patients in their series had disc degeneration in the infrajacent disc (L5-S1) that required the extension of fusion to the sacrum. Their report challenged the pre-existing traditional belief that lower lumbar fusions, as a rule, should extend to include the lumbosacral segment. Ghiselli et al. [4] reported a similar experience with floating L4-L5 fusions more recently in which none of their 32 patients required the extension of fusion to the sacrum after a mean followup period of 7.3 years. Only one patient required decompression at the L5-S1 segment for radicular symptoms.

However, the reported outcomes of floating fusions in other studies appear to contradict the conclusions of the above studies. Bydon et al. [5], in a large cohort of 511 patients, compared the outcomes of floating lumbar fusions and fusions extending to the lumbosacral junction (performed over a period of 23 years) and concluded that floating fusions were significantly more likely to develop ASD than fusions extending to the lumbosacral junction. They found no significant difference in the ASD rates in the discs suprajacent to the fusion in both floating fusions and fusions extending to the sacrum. The ASD rates in the discs infrajacent to the fusion were significantly different between the two groups, with relatively high ASD rates in the floating fusion group. Miyakoshi et al. [6] evaluated the outcomes of posterior lumbar interbody floating fusions in 45 patients with over 5 years of follow-up and reported decreased height of both the suprajacent and infrajacent discs. No correlation was reported between imaging and clinical outcomes.

The present study aimed to employ finite element (FE) analysis to determine the magnitude of stress on the discs adjacent to a monosegmental, instrumented, and noninstrumented floating lumbar fusion of the L4-L5 spinal segment.

\section{Materials and Methods}

The steps followed for developing the FE models of the spine, including the baseline model and the models incorporating surgical interventions, are shown in the flow chart in Fig. 1.
The FE modeling of the truncated vertebral unit (TVU): using the image processing software MIMICS, a 3D geometric model of the lumbar spine was generated from the computed tomography (CT) scan images of an adult male human subject. An FE model of the TVU for analysis using the advanced explicit nonlinear FE analysis tool LSDYNA was then developed to obtain the compressive force-displacement response under quasi-static and impact loading conditions. This FE model comprised 22,511 elements and is shown in Fig. 2 with the key parts highlighted. It should be noted that the outer cortical bone and the end plates were modeled with 3,516 shell elements,

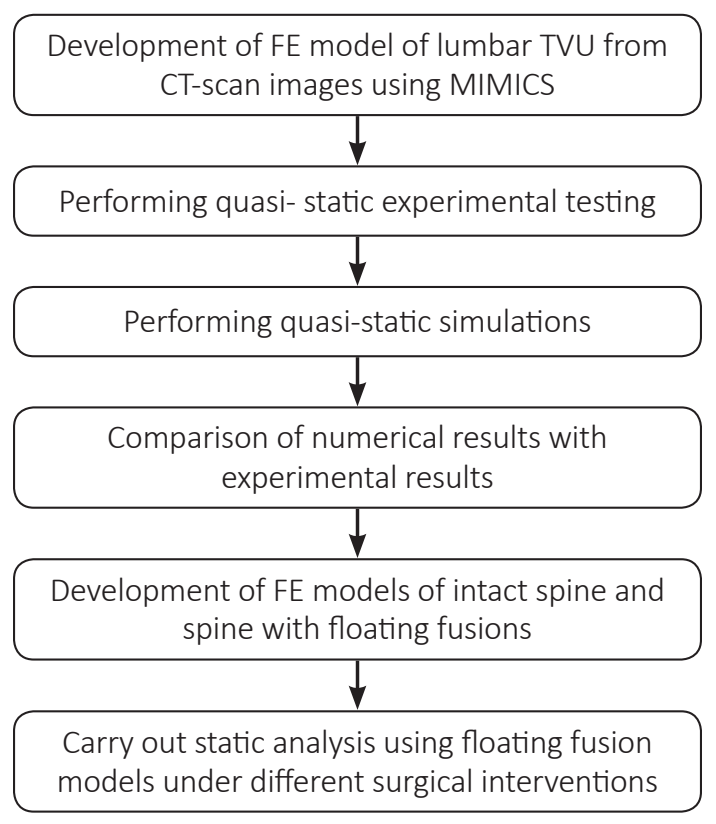

Fig. 1. Flow chart of the methodology employed in the present study. FE, finite element; TVU, truncated vertebral unit; CT, computed tomography.

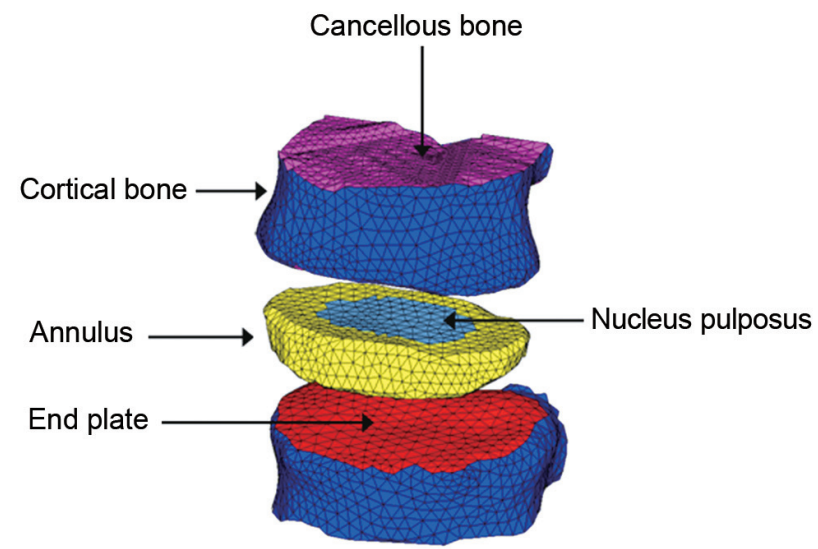

Fig. 2. Finite element model of truncated vertebral unit (exploded view). 
Table 1. Material properties assumed for bony vertebrae and disc

\begin{tabular}{|c|c|c|c|c|c|}
\hline \multirow{3}{*}{ Mechanical property } & \multicolumn{5}{|c|}{ Component } \\
\hline & \multicolumn{3}{|c|}{ Vertebral body } & \multicolumn{2}{|r|}{ Disc } \\
\hline & Cortical bone & Cancellous bone & End plate & Annulus & Nucleus pulposus \\
\hline Young's modulus (MPa) & 11,000 & 100 & 1,000 & 10 & 1 \\
\hline Poisson's ratio & 0.31 & 0.3 & 0.31 & 0.45 & 0.45 \\
\hline Strength (MPa) & 150 & 6 & 15 & & 2.6 \\
\hline
\end{tabular}

whereas the vertebral body and the intervertebral disc were modeled using 18,995 solid elements.

For the purpose of the present study, the mechanical behaviors of various tissues (Fig. 2) were represented with MAT 24 (piecewise linear plasticity models in LS-DYNA). Although bone is a composite material that exhibits orthotropy and inhomogeneity, modeling bone as an isotropic and homogenous material has a minimum effect on the accuracy of the results, with the most appropriate densityelasticity relationship of the bone tissue being specimenspecific. The properties of the material used are listed in Table 1. The values of the modulus and strength of cancellous bone and end plates presented in Table 1 were obtained from tests performed in the present study, whereas the properties of other tissues, i.e., the cortical bone and disc, were estimated based on the data reported in the literature $[7,8]$. The interface identified using the keyword Contact_Automatic_General in LS-DYNA was activated to capture contacts between various parts of the TVU model.

Experimental testing: in the present study, experimental investigation into the load-displacement responses of a human lumbar TVU under quasi-static loading conditions was performed. TVU samples obtained from the lumbar spinal column of an adult human male cadaver were subjected to quasi-static compressive tests in a UTM. The experimental characterizations of the elasto-plastic behavior of the L1-L2 TVU and L2-L3 TVU under quasistatic axial compressive loading were performed. The TVU under axial compression is shown in Fig. 3.

Quasi-static simulation: in the simulation of the UTMbased quasi-static compression test (Fig. 4), the top plate was provided a small steady downward velocity, and analysis was performed for a sufficiently long time. The variation in the resultant force generated between the top plate and the TVU (Fig. 4) with respect to the corresponding vertical displacement of the plate is compared with the experimental force-displacement curve, as shown in Fig. 5.

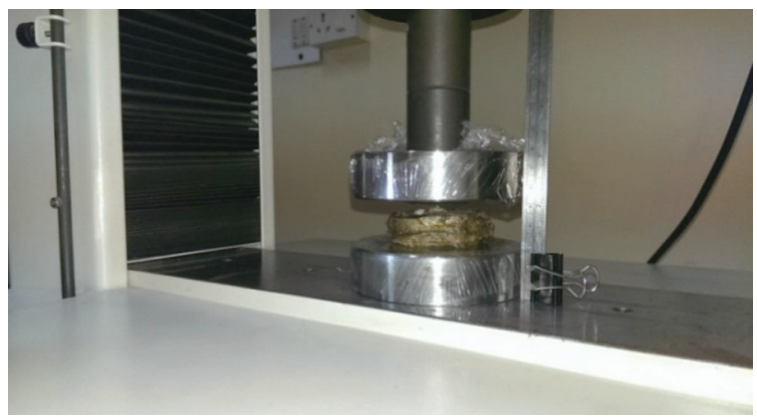

Fig. 3. Experimental test setup.

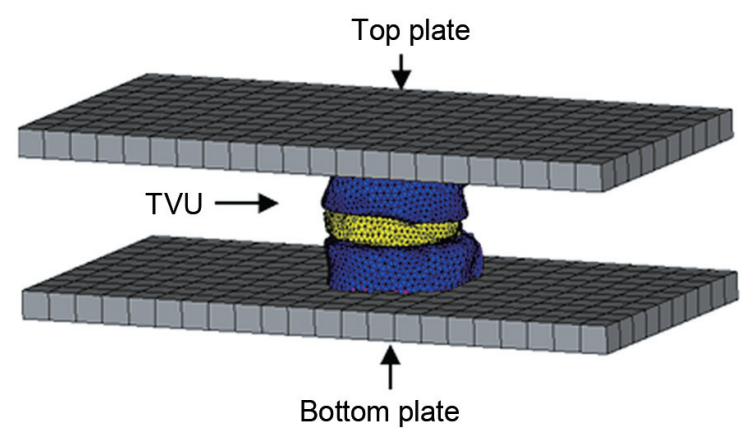

Fig. 4. Simulation of truncated vertebral unit (TVU) under compression.

Fig. 5 shows that the computed force-displacement curve is in good agreement with the test-based behavior. Thus, the FE modeling procedure adopted for the analysis of the TVU could be applied with confidence in simulationdriven studies.

Development of the FE model of the intact lumbar spine: the FE model of the lumbar spine was developed from the relevant CT scan images using MIMICS. Fig. 6A shows the anterior and lateral views of the model, and Fig. $6 \mathrm{~B}$ shows the detailed nomenclature for bony and soft tissue elements. The properties of the soft tissues and bony vertebral elements were obtained from the literature [913]. The soft tissues were modeled using MAT 91 (transversely isotropic hyperelastic model), representing an 


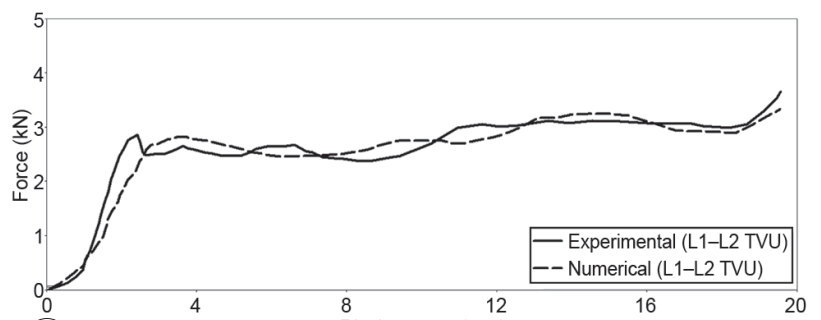

(A)

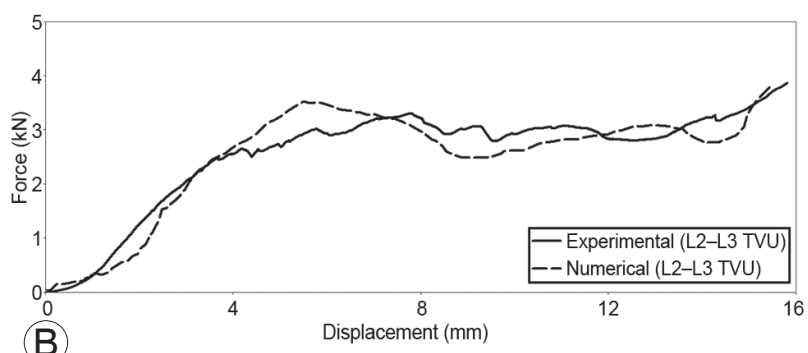

Fig. 5. Comparison of quasi-static response of a truncated vertebral unit (TVU). (A) Force versus displacement response of L1-L2 TVU. (B) Force versus displacement response of L2-L3 TVU.

isotropic Mooney-Rivlin matrix with fiber reinforcement and strain energy characteristics similar to the qualitative material behavior of collagen. The material properties of the various soft tissues used in the present model are shown in Tables 2 and 3.

The intervertebral discs were modeled using higher order tetrahedral elements with an average element edge length of $1.5 \mathrm{~mm}$. The ligaments and cortical bone were modeled using shell elements. The intact (no-fusion)

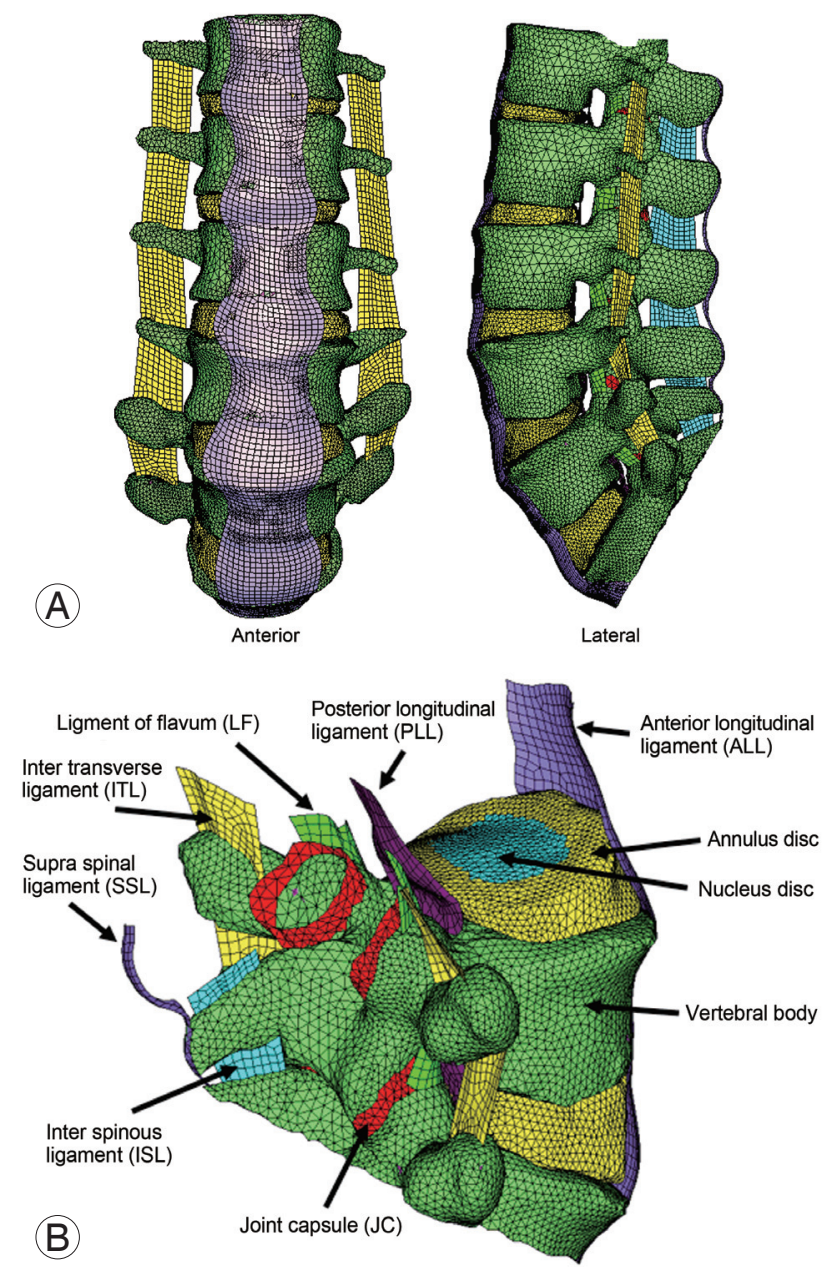

Fig. 6. (A) Finite element model of the lumbar spine. (B) Nomenclature of bony and soft tissue elements.

Table 2. Material properties of soft tissues for use in MAT 91 (LS-DYNA material model)

\begin{tabular}{|c|c|c|c|c|c|c|c|}
\hline $\begin{array}{l}\text { Material } \\
\text { properties }\end{array}$ & $\begin{array}{l}\text { Density } \\
\left(\mathrm{kg} / \mathrm{m}^{3}\right)\end{array}$ & $\begin{array}{l}\text { Bulk modulus } \\
(\mathrm{MPa})\end{array}$ & $\begin{array}{l}\text { Poisson } \\
\text { ratio }(v)\end{array}$ & $\mathrm{C} 1$ (MPa) & $\mathrm{C} 3$ (MPa) & C4 & $\mathrm{C} 5$ (MPa) \\
\hline ALL & 1,000 & 4 & 0.4 & 0.095 & 0.8 & 4.077 & 14.05 \\
\hline PLL & 1,000 & 3.2 & 0.4 & 0.17 & 0.60 & 11.88 & 19.24 \\
\hline ITL & 1,000 & 4 & 0.4 & 0.095 & 0.8 & 4.077 & 14.05 \\
\hline SSL & 1,000 & 3.2 & 0.4 & 0.17 & 0.60 & 11.88 & 19.24 \\
\hline
\end{tabular}

ALL, anterior longitudinal ligament; PLL, posterior longitudinal ligament; ITL, inter transverse ligament; SSL, supraspinous ligament.

Table 3. Material properties of soft tissues for use in MAT 24 (LS-DYNA material model)

\begin{tabular}{|c|c|c|c|c|c|}
\hline $\begin{array}{l}\text { Material } \\
\text { properties }\end{array}$ & $\begin{array}{l}\text { Density } \\
\left(\mathrm{kg} / \mathrm{m}^{3}\right)\end{array}$ & $\begin{array}{l}\text { Young's modulus } \\
\text { (MPa) }\end{array}$ & Poisson ratio $(v)$ & $\begin{array}{l}\text { Yield strength } \\
\qquad(\mathrm{MPa})\end{array}$ & $\begin{array}{c}\text { Tangent modulus } \\
\text { (MPa) }\end{array}$ \\
\hline ISL & 1,000 & 4.56 & 0.4 & 1.5 & 4 \\
\hline $\mathrm{FC}$ & 1,000 & 22.8 & 0.4 & 27.4 & 20.9 \\
\hline LF & 1,000 & 5.7 & 0.4 & 1.5 & 5 \\
\hline
\end{tabular}

ISL, interspinous ligament; FC, facet capsule; LF, ligamentum flavum. 
lumbar spine model (L1-S1) shown in Fig. 6A was used as the baseline model. The loads and boundary conditions applied are shown in Fig. 7. A load of $350 \mathrm{~N}$ magnitude representing the upper body weight was applied $200 \mathrm{~mm}$ cranial and $30 \mathrm{~mm}$ ventral to the T12-L1 disc center, and a compressive follower load of $500 \mathrm{~N}$ was applied to simulate the effect of the local muscles. These loads were consistent with those used in the study by Calisse et al. [7] and Rohlmann et al. [14]. For flexion, a load of $50 \mathrm{~N}$ was applied at the rectus abdominis muscle location, with a vertical upper body load of $260 \mathrm{~N}$ and a follower load of $200 \mathrm{~N}$. For extension, a load of $500 \mathrm{~N}$ was applied at the erector spinae muscle location, with a vertical upper body load of $260 \mathrm{~N}$ and a follower load of $200 \mathrm{~N}$.

Development of the FE models of the lumbar spine with floating fusions: using the calibrated intact spine FE model, various other models were developed to mimic variations in floating fusion. These included posterior fusion without instrumentation, posterior fusion with pedicle screw instrumentation, posterior lumbar interbody fusion (PLIF) with instrumentation (stand-alone cages), and combined anterior and posterior $\left(360^{\circ}\right)$ fusion with instrumentation. Fig. 8A shows the lumbar spine FE models representing L4-L5 posterior floating fusion without instrumentation. In this model, a posterolateral bone graft was added to fuse the segment, and decompression was performed by removing the corresponding spinous processes, laminae, medial half of the facet joints, supraspinous ligament, interspinous ligament, intertransverse ligament, ligamentum flavum, and part of the facet capsule. Fig. 8B shows the FE model representing the posterior spinal decompression and fusion with pedicle screw instrumentation. Fig. 8C shows the FE model representing decompression and floating fusion using PLIF with cages. In these models, interbody bone cages with grafts were added to fuse the relevant segments. Fig. $8 \mathrm{D}$ shows a circumferential floating fusion model (combined anterior and posterior or $360^{\circ}$ fusion) at the L4-L5 level. In this model, posterior decompression and pedicle screw instrumentation were combined with anterior instrumentation using a cage with bone grafts. The boundary and loading conditions for the models with fusion were the same as the conditions used for the intact spine model.

\section{Results}

Stress distributions in the discs suprajacent and infrajacent to the L4-L5 disc were obtained for different types of interventions under static, flexion, and extension loading conditions. The location of the increased stress in the suprajacent and infrajacent discs was in the annulus fibrosus zone of the disc. The magnitudes of stress at the adjacent levels during different types of interventions at different levels of fusion were compared with those in the baseline no-fusion model. Table 4 shows the absolute values of the stress and the percentage increase over the baseline
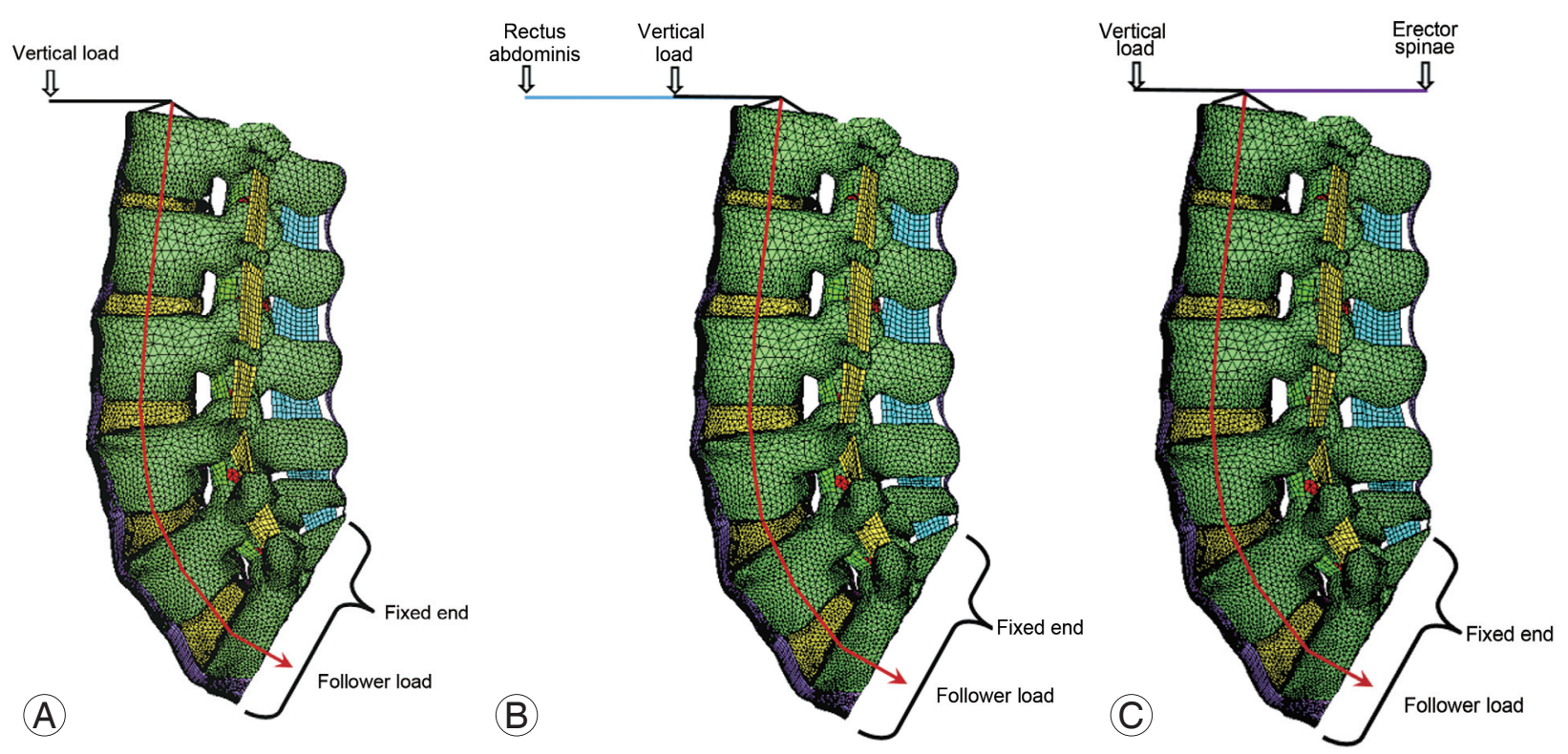

Fig. 7. (A) Loads and boundary conditions for static model. (B) Loads and boundary conditions for flexion model. (C) Loads and boundary conditions for extension model. 

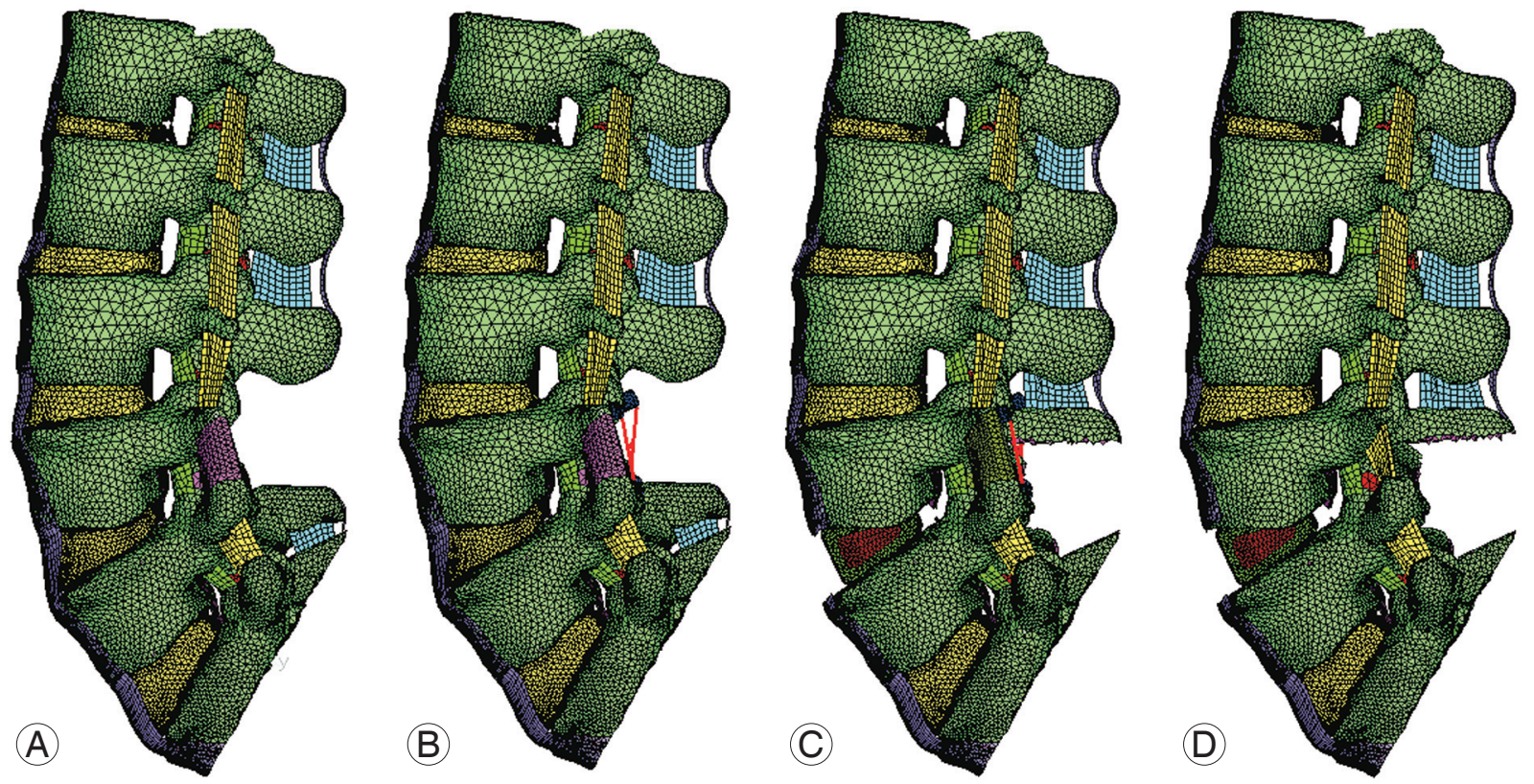

Fig. 8. Finite element models of the lumbar spine with floating fusion variations in L4-L5 disc. (A) Posterior fusion without instrumentation. (B) Posterior fusion with pedicle screw instrumentation. (C) Posterior lumbar interbody fusion (PLIF). (D) Combined anterior and posterior fusion (360 fusion).

Table 4. Results of finite element analysis of the baseline and intervention models (stresses in the upper and lower discs adjacent to the floating fusion and the percentage increase in the stresses)

\begin{tabular}{|c|c|c|c|c|}
\hline $\begin{array}{l}\text { Type of interventions/position of } \\
\text { lumbar spine }\end{array}$ & $\begin{array}{l}\text { L5-S1 } \\
\text { (MPa) }\end{array}$ & $\begin{array}{c}\text { Percentage } \\
\text { increase in L5-S1 }\end{array}$ & $\begin{array}{l}\mathrm{L} 3-\mathrm{L} 4 \\
(\mathrm{MPa})\end{array}$ & $\begin{array}{c}\text { Percentage } \\
\text { increase L3-L4 }\end{array}$ \\
\hline \multicolumn{5}{|l|}{ Baseline model } \\
\hline Static & 1.79 & - & 0.7 & - \\
\hline Flexion & 2.05 & - & 1.24 & - \\
\hline Extension & 2.13 & - & 1.56 & - \\
\hline \multicolumn{5}{|l|}{ Posterior fusion without instrumentation } \\
\hline Static & 1.8 & 0.5 & 0.72 & 2.8 \\
\hline Flexion & 2.24 & 9.2 & 1.73 & 39.5 \\
\hline Extension & 1.97 & 7.5 & 1.79 & 14.7 \\
\hline \multicolumn{5}{|l|}{ Posterior fusion with instrumentation } \\
\hline Static & 1.73 & 3.3 & 0.73 & 4.2 \\
\hline Flexion & 2.23 & 8.8 & 1.77 & 42.7 \\
\hline Extension & 1.65 & 22.5 & 1.81 & 16 \\
\hline \multicolumn{5}{|l|}{ Anterior fusion with instrumentation } \\
\hline Static & 1.77 & 1.1 & 0.76 & 8.5 \\
\hline Flexion & 2.33 & 13.6 & 1.75 & 41.1 \\
\hline Extension & 1.87 & 12.2 & 1.55 & 0.6 \\
\hline \multicolumn{5}{|l|}{360 (Anterior+posterior instrumentation) } \\
\hline Static & 1.7 & 5 & 0.8 & 14.2 \\
\hline Flexion & 2.2 & 7.3 & 1.76 & 41.9 \\
\hline Extension & 1.43 & 32.8 & 1.52 & 2.5 \\
\hline
\end{tabular}


model. Stress plots for the maximum Von Mises stress are shown in Fig. 9.

Posterolateral noninstrumented fusion: the stress on the infrajacent disc (L5-S1) increased by $0.5 \%, 9.5 \%$, and $7.2 \%$ under static, flexion, and extension loading conditions, respectively, and that on the suprajacent disc (L3-L4) increased by $2.8 \%, 39.8 \%$, and $14.7 \%$ under static, flexion, and extension loading conditions, respectively.

PLIF with instrumentation (cages): the stress on the infrajacent disc (L5-S1) increased by $1.1 \%, 13.6 \%$, and $12.2 \%$ under static, flexion, and extension loading conditions, respectively, and that on the suprajacent disc (L3L4) increased by $8.5 \%, 41.1 \%$, and $0.6 \%$ under static, flex- ion, and extension loading conditions, respectively.

Posterolateral instrumented fusion with pedicle screws: the stress on the infrajacent disc (L5-S1) increased by $3.3 \%, 8.8 \%$, and $22.5 \%$ under static, flexion, and extension loading conditions, respectively, and that on the suprajacent disc (L3-L4) increased by $4.2 \%, 42.7 \%$, and $16 \%$ under static, flexion, and extension loading conditions, respectively.

Combined anterior and posterior fusion with instrumentation $\left(360^{\circ}\right.$ fusion): the stress on the infrajacent disc (L5-S1) increased by $5 \%, 7.3 \%$, and $32.8 \%$ under static, flexion, and extension loading conditions, respectively, and that on the suprajacent disc (L3-L4) increased by
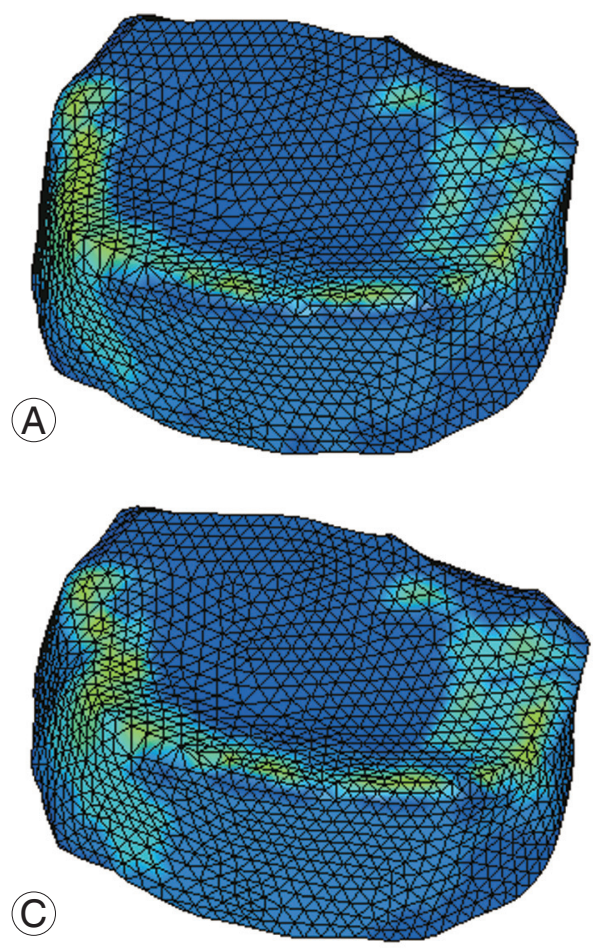

Fringe levels
$1.789 \mathrm{e}+00$
$1.611 \mathrm{e}+00$
$1.433 \mathrm{e}+00$
$1.256 \mathrm{e}+00$
$1.078 \mathrm{e}+00$
$9.003 \mathrm{e}-01$
$7.227 \mathrm{e}-01$
$5.450 \mathrm{e}-01$
$3.673 \mathrm{e}-01$
$1.897 \mathrm{e}-01$
$1.200 \mathrm{e}-02$
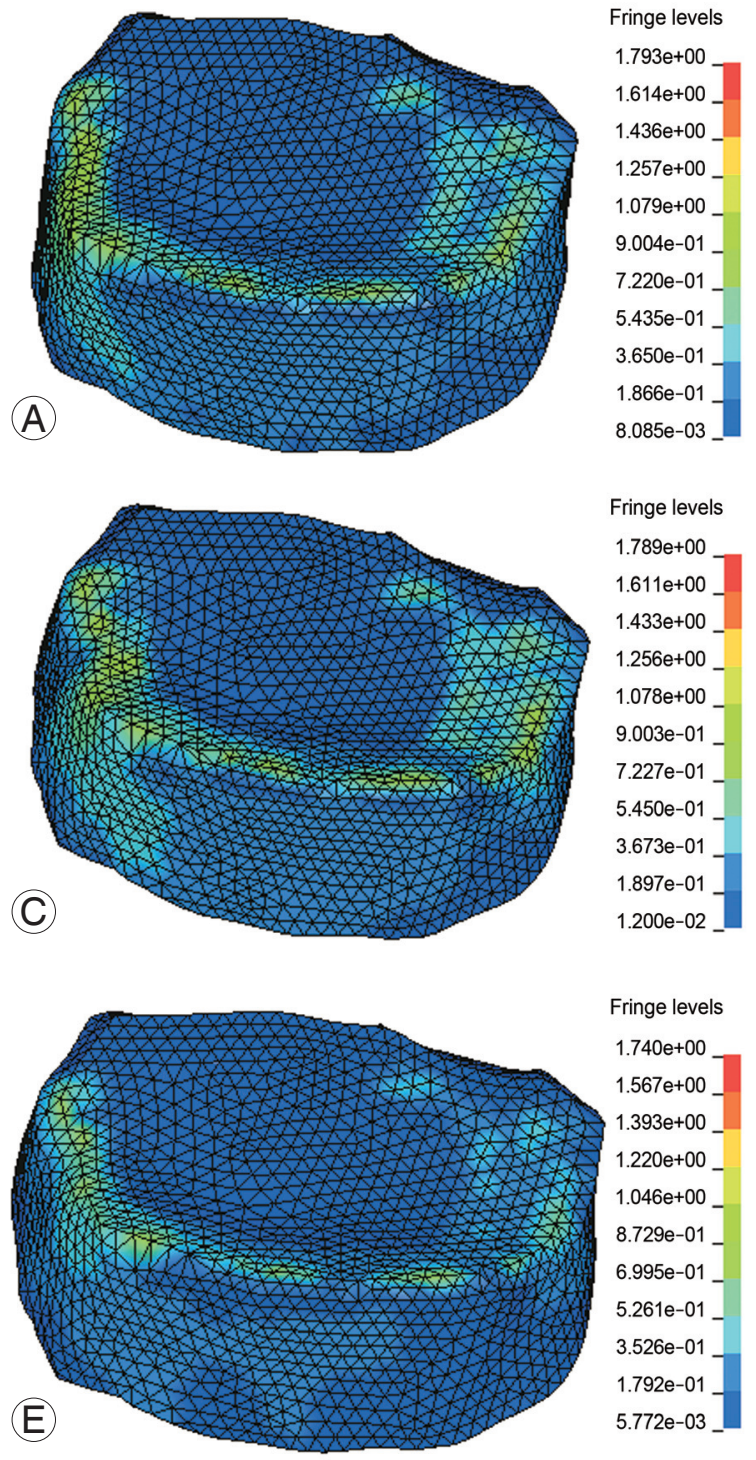

(B)
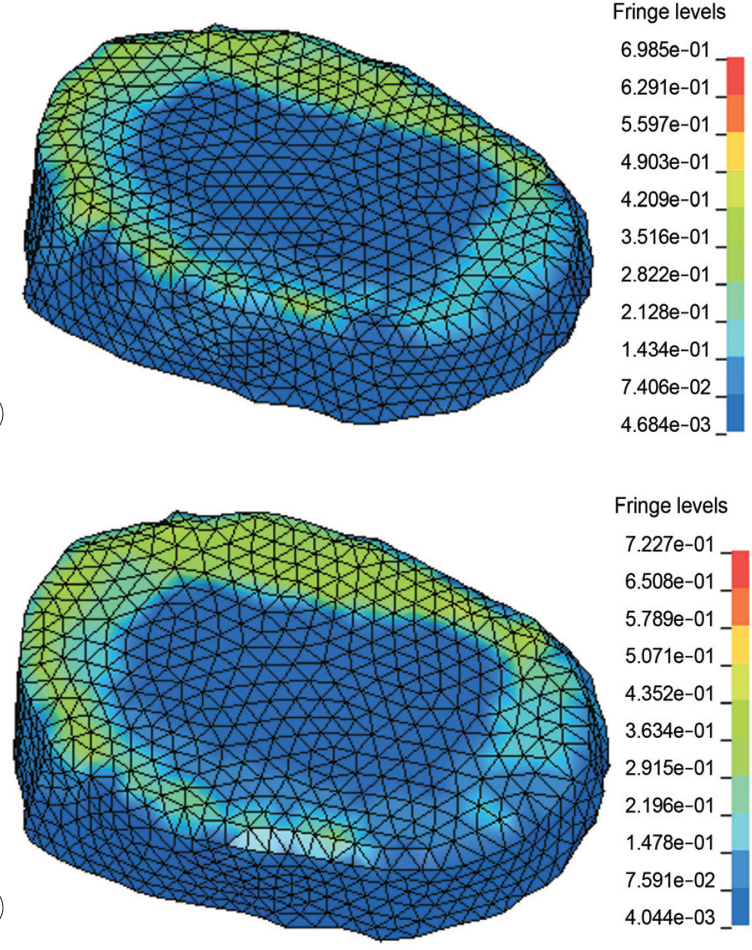

Fringe levels

$7.227 \mathrm{e}-01$

$6.508 \mathrm{e}-01$

$5.789 \mathrm{e}-01$

$5.071 \mathrm{e}-01$

$4.352 e-01$

$3.634 \mathrm{e}-01$

$2.915 \mathrm{e}-01$

2.196e-01

$1.478 \mathrm{e}-01$

$7.591 \mathrm{e}-02$

$4.044 \mathrm{e}-03$

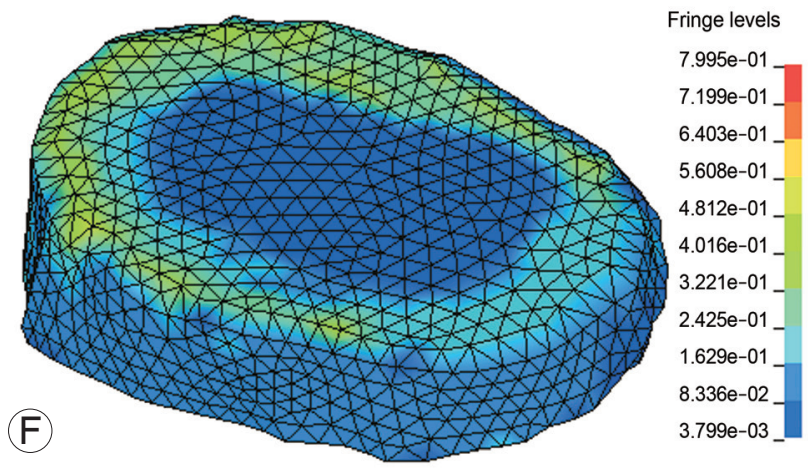

Fig. 9. Stress contours obtained for intervertebral discs from various finite element models. (A, B) Baseline no-fusion L5-S1 and L3-L4. (C, D) Posterior fusion with instrumentation. (E, F) $360^{\circ}$ (Anterior+posterior) instrumentation. 
$14.2 \%, 41.9 \%$, and $2.5 \%$ under static, flexion, and extension loading conditions, respectively.

\section{Discussion}

Although ASD has been extensively studied, to date, ASD in floating lumbar fusions has been the subject of few studies. Disch et al. [15] reported a higher incidence of adjacent segment degeneration following floating L4-L5 fusions than that following L5-S1 and L4-S1 fusions over a mean follow-up period of 14 years. There seems to be a consensus that the adjacent disc cranial to the floating fusion (suprajacent disc) exhibits a high incidence of ASD (5\%-70\% incidence) following lumbar spine floating fusions. However, there is a lack of consensus regarding the extent of the effects of floating fusion on the disc infrajacent to the floating fusion (infrajacent disc). To date, the studies on long-term and medium-term clinical and imaging outcome have reported contradictory conclusions on the effects of floating fusion on the adjacent discs, especially the infrajacent disc. It is essential to clarify the effects of floating fusion on the infrajacent disc because the information will enable the surgeon to determine whether to limit the fusion to L5 and extend it to the sacrum.

In addition to $\mathrm{ASD}$, postoperative radiculopathy due to infrajacent disc degeneration following floating fusions has also been the focus of few studies. Bydon et al. [5] reported a high incidence of ASD in the infrajacent disc following floating fusion but found a significantly low incidence of postoperative radiculopathy in these patients. Fusions to the sacrum are reportedly associated with a high incidence of reoperations for postoperative radiculopathy. Inoue et al. [16] and Miyakoshi et al. [6] have reported a significantly high incidence of decrease in the L5-S1 disc height following floating fusions at the L4-L5 level, which was not associated with significant clinical abnormalities in their studies. They attributed the decrease in the infrajacent disc height to increased stress in the disc after the floating fusion of the upper disc. Mesfin and Lemma [17] reported a bilateral pars fracture of L5 following the floating fusion of the L4-L5 disc in a patient with rheumatoid arthritis. These reports suggest that floating fusion causes ASD in the infrajacent disc, which does not correlate significantly with the symptoms of radiculopathy. However, in a recent study by Orita et al. [18], a $6.4 \%$ incidence of postoperative L5 radiculopathy was observed following floating fusion. The authors reported that multilevel floating fusions, male sex, and preoperative imaging abnormalities in the L5-S1 disc are associated with a high likelihood of postoperative radiculopathy and recommended fusion to the sacrum in the presence of preoperative abnormalities, such as coronal plane wedging and foraminal narrowing, in the L5-S1 disc.

In the present study, we compared the stress in the discs in the baseline no-fusion FE model with that in the fusion models. The important observation in our study was that stress increased in both the suprajacent and infrajacent discs following floating L4-L5 fusion. The increase in stress was between $0.5 \%$ and $5 \%$ in the infrajacent disc (L5-S1) and between $2.8 \%$ and $14.5 \%$ in the suprajacent disc (L3-L4) under static loading conditions. The stress was much higher following fusion in the flexion and extension loading conditions than in the static loading conditions. During flexion, the stress increased by $8.8 \%-$ $13.6 \%$ in the infrajacent disc and by $39.5 \%-42.7 \%$ in the suprajacent disc. During extension, the stress increased by $7.5 \%-2.8 \%$ in the infrajacent disc and by $0.6 \%-16 \%$ in the suprajacent disc. Thus, the stress on the suprajacent disc is high in magnitude, but the infrajacent disc also experienced increased stress following floating fusion. Our findings are similar to those reported by Shin et al. [19] who stated increased stress in both the superior and inferior discs adjacent to the fusion segment. Their study involved a comparison between dynamic fusion and conventional instrumented fusion for lumbar spinal stabilization. Our study was focused on the effects of the subtypes (anterior, posterior, and combined) of fixed fusion on the adjacent discs. It is clear that all types of conventional instrumented floating fusions are associated with increased stress on the suprajacent and infrajacent discs. Chen et al. [8] also reported increased stress in both the suprajacent and infrajacent discs following floating anterior lumbar interbody fusion. Similar to the findings in our study, the stress in their study was higher in the suprajacent disc than in the infrajacent disc. Chen et al. [8] also reported higher levels of adjacent disc stress in longer (multisegmental) floating fusions and floating fusions involving lower lumbar segments than in upper lumbar segments.

Apart from pre-existing degenerative changes, other factors implicated in the degeneration of the disc infrajacent to a floating fusion include long fusion (polysegmental fusion) and rigidity of the fusion. Previous long-term studies on long segment thoracolumbar fusions for scoliosis that stopped short of the L4-L5 or L5-S1 segment 
reported a high incidence of degenerative changes in the unfused disc below the level of the fusion [20,21].

In general, a higher incidence of ASD has been reported in instrumented fusions than in noninstrumented fusions. In their FE study, Jin et al. [22] assessed the effect of the rigidity of fusions, especially floating fusions. Increasing the rigidity of the fusion was associated with an increase in the stress in both suprajacent and infrajacent discs. However, the authors noted that the increased rigidity of instrumentation was associated with incremental stress on the suprajacent disc, whereas all types of instrumentation had similar effects on the infrajacent disc. In our study, the stress on the suprajacent disc increased with all types of instrumentation and was the highest following combined anterior and posterior fusion. The stress on the infrajacent disc also increased with instrumentation and varied according to the type of instrument (the lowest overall increase in stress following PLIF and the highest stress following $360^{\circ}$ fusion).

\section{Conclusions}

It appears clear that both the suprajacent and infrajacent discs experience increased stress and exhibit changes in ASD over the long term, although the stress is higher on the disc suprajacent to the floating fusion than on the disc infrajacent to the fusion. Instrumentation (more rigid fusion) appears to increase the stress on both the suprajacent and infrajacent discs, but the magnitude of stress in higher on the suprajacent disc than on the infrajacent disc.

\section{Conflict of Interest}

No potential conflict of interest relevant to this article was reported.

\section{References}

1. Derincek A, Mehbod A, Pinto M, Transfeldt E. Degeneration of non-fused segments after floating lumbar fusion. Acta Orthop Belg 2008;74:507-11.

2. Rousseau MA, Lazennec JY. Degenerative disease supra- and infra-jacent to fused lumbar and lumbosacral levels. Orthop Traumatol Surg Res 2016;102(1 Suppl):S1-8.

3. Brodsky AE, Hendricks RL, Khalil MA, Darden BV, Brotzman TT. Segmental ("floating") lumbar spine fusions. Spine (Phila Pa 1976) 1989;14:447-50.

4. Ghiselli G, Wang JC, Hsu WK, Dawson EG. L5-S1 segment survivorship and clinical outcome analysis after L4-L5 isolated fusion. Spine (Phila Pa 1976) 2003;28:1275-80.

5. Bydon M, Xu R, Santiago-Dieppa D, et al. Adjacentsegment disease in 511 cases of posterolateral instrumented lumbar arthrodesis: floating fusion versus distal construct including the sacrum. J Neurosurg Spine 2014;20:380-6.

6. Miyakoshi N, Abe E, Shimada Y, Okuyama K, Suzuki T, Sato K. Outcome of one-level posterior lumbar interbody fusion for spondylolisthesis and postoperative intervertebral disc degeneration adjacent to the fusion. Spine (Phila Pa 1976) 2000;25:1837-42.

7. Calisse J, Rohlmann A, Bergmann G. Estimation of trunk muscle forces using the finite element method and in vivo loads measured by telemeterized internal spinal fixation devices. J Biomech 1999;32:727-31.

8. Chen CS, Cheng CK, Liu CL, Lo WH. Stress analysis of the disc adjacent to interbody fusion in lumbar spine. Med Eng Phys 2001;23:483-91.

9. Robertson D, Willardson R, Parajuli D, Cannon A, Bowden AE. The lumbar supraspinous ligament demonstrates increased material stiffness and strength on its ventral aspect. J Mech Behav Biomed Mater 2013;17:34-43.

10. Hortin M, Graham S, Boatwright K, Hyoung P, Bowden A. Transversely isotropic material characterization of the human anterior longitudinal ligament. J Mech Behav Biomed Mater 2015;45:75-82.

11. Kirby MC, Sikoryn TA, Hukins DW, Aspden RM. Structure and mechanical properties of the longitudinal ligaments and ligamentum flavum of the spine. J Biomed Eng 1989;11:192-6.

12. El-Rich M, Arnoux PJ, Wagnac E, Brunet C, Aubin $\mathrm{CE}$. Finite element investigation of the loading rate effect on the spinal load-sharing changes under impact conditions. J Biomech 2009;42:1252-62.

13. Cyron BM, Hutton WC. The tensile strength of the capsular ligaments of the apophyseal joints. J Anat 1981;132(Pt 1):145-50.

14. Rohlmann A, Bauer L, Zander T, Bergmann G, Wilke HJ. Determination of trunk muscle forces for flexion and extension by using a validated finite element model of the lumbar spine and measured in vivo data. J Biomech 2006;39:981-9. 
15. Disch AC, Schmoelz W, Matziolis G, Schneider SV, Knop C, Putzier M. Higher risk of adjacent segment degeneration after floating fusions: long-term outcome after low lumbar spine fusions. J Spinal Disord Tech 2008;21:79-85.

16. Inoue G, Takaso M, Miyagi M, et al. Risk factors for L5-S1 disk height reduction after lumbar posterolateral floating fusion surgery. J Spinal Disord Tech 2014;27:E187-92.

17. Mesfin A, Lemma MA. Bilateral pars fractures complicating long fusion to L5 in a patient with rheumatoid arthritis. Spine (Phila Pa 1976) 2011;36:E882-5.

18. Orita S, Yamagata M, Ikeda Y, et al. Retrospective exploration of risk factors for L5 radiculopathy following lumbar floating fusion surgery. J Orthop Surg Res 2015;10:164.

19. Shin DS, Lee K, Kim D. Biomechanical study of lumbar spine with dynamic stabilization device using finite element method. CAD Comput Aided Des 2007;39:559-67.

20. Kuhns CA, Bridwell KH, Lenke LG, et al. Thoracolumbar deformity arthrodesis stopping at L5: fate of the L5-S1 disc, minimum 5-year follow-up. Spine (Phila Pa 1976) 2007;32:2771-6.

21. Edwards CC 2nd, Bridwell KH, Patel A, et al. Thoracolumbar deformity arthrodesis to L5 in adults: the fate of the L5-S1 disc. Spine (Phila Pa 1976) 2003;28:2122-31.

22. Jin YJ, Kim YE, Seo JH, Choi HW, Jahng TA. Effects of rod stiffness and fusion mass on the adjacent segments after floating mono-segmental fusion: a study using finite element analysis. Eur Spine J 2013;22:1066-77. 